\title{
EDITORIAL POLICY STATEMENT
}

The Eastern Journal of Psychiatry (EJP) - an official publication of the Indian Psychiatric Society (IPS) is published on a half yearly basis. It strives to publish a wide range of articles of interest to psychiatrists, other mental health professionals, clinicians, students and individuals from allied fields. It also seeks to educate its readers and encourage research from various quarters.

\section{General policies}

The EJP substantively follows the guidelines laid down by the International Committee of Medical Journal Editors (http://www.inmje.org).

This requires the manuscripts to present an original piece of work that has not been published previously or submitted for publication elsewhere, and has been approved by each author. Authors submitting papers with a common theme or using data derived from the same sample must furnish details of all relevant previous publications, submissions and papers in preparation.

\section{Authorship}

The authors for the manuscripts must be mentioned explicitly. To qualify for authorship, each author should have participated sufficiently in the work to take public responsibility for the content. Each author must have made substantial contributions to (i) the conception and design or analysis and interpretation of data; (ii) drafting the article or revising it critically for important intellectual content; and (iii) the final approval of the material to be published. It is essential for the requirement in (iii) to be satisfied with one of the requirements in (i) or (ii). Participation limited to funding or collection of data or general supervision of the research group does not qualify for authorship.

All authors must sign the covering letter and one of them should be assigned to receive correspondence at a clearly stated address. This author for correspondence should be responsible for keeping all other authors informed of the paper's progress. It is imperative that the authorship is agreed upon among the study's workers, contributors of additional data and other interested parties, before submission of the manuscript.

\section{Copyright transfer}

The approval of manuscript submission by all authors implies the transfer of copyright to the Indian Psychiatric society. The articles cannot be published elsewhere, in full or in part, without the written permission of the Editor. Authors must obtain letters of permission from publishers for the use of quotations (more than 500 words) or figures that have been published elsewhere.

\section{Source of funding, all stake holders}

All forms of support, including drug company support, shall be acknowledged.

\section{Conflict of interest}

Authors must disclose any commercial or financial involvements that might present an appearance of a conflict of interest in connection with the submitted manuscript.

\section{Ethical aspects}

All research requiring informed consent should have done so appropriately and must clearly document the same. All aspects of confidentiality must also be adhered to, specifically by concealing/modifying all identification details of individuals.

\section{Process of review}

Original research papers, brief research communication and case reports will be peer reviewed. Articles in other sections including viewpoint, commentaries will be either invited and/ or reviewed, and suitably modified from the submissions made. Feedback/ comments of the reviewers will be communicated to the authors within three months of receipt. All reviewers will remain anonymous for the concerned authors. For book review the renewer will be named with all his details and will remain numerous to the authors.

\section{Reprints}

In routine practice hardcopy reprints will not be provided. Soft copies of the articles will be available on the internet and if required will be provided to the contributor from the editorial office.

\section{GUIDELINES FOR CONTRIBUTORS}

\section{Manuscripts}

The authors should submit three (3) neatly typed hard copies of the manuscript (double-spaced throughout) along with an electronic version in a CD (soft copy) to the editorial office. The requirements of the Eastern Journal of Psychiatry are summarized below: 


\section{General}

All correspondence will be made with the author specified for that purpose. Manuscripts should be accompanied by a covering letter indicating that the paper is intended for publication, stating the number of figures and tables, and the number of words in the manuscript. The preference for the section cited in the Journal will be actively considered along with an assessment by the Editor and the editorial team to decide on the most suitable section for each submission, in consultation with the author. Papers not in accordance with the requisite format, or those which do not meet the requirements for one of the types of articles specified, will neither be sent for peer review nor be returned to the author. Suggestions for resubmission may be communicated to the authors. Manuscripts found unsuitable for publication will not be returned.

The author will be notified on receipt of their manuscript and a number will be assigned to it. The number must be mentioned in all future correspondence. The author must inform Editorial office about the change of address, if any. The address of Editorial Office is Dr. Anil Kumar, L-23, Shyamali Colony, P. O. Doranda, Ranchi-834002.

\section{Types of manuscripts and word limits}

1. Original Research Papers: These should only include original findings from high-quality planned research studies such as experimental designs, outcome studies, case-control series and surveys with high response rates, randomised controlled trials, intervention studies, studies of screening and diagnostic tests, and cost-effectiveness analyses. The word limit is 5000 excluding references and an abstract (structured format) of not more than 250 words.

2. Brief Research Communication: These manuscripts, with not more than I table/figure, should contain short reports of original studies or evaluations, service-oriented research which may not be methodologically sound but points towards a potential area of scientific research or unique first-time reports. The word limit is 1500 words and up to 20 references, and an abstract (structured format) of not more than 150 words.

3. Case Reports: These should contain reports of new/ interesting/rare cases of clinical significance or with implications for management. The word limit is 1500 words and up to 10 references, and an abstract of not more than 150 words.
4. Review Articles (invited): These are systemic and critical assessments of the literature which will be invited. Review articles should include an abstract of not more than 250 words describing the purpose of the review, collection and analysis of data, with the main conclusions. The word limit is 5000 words excluding references and abstract.

5. Letters to the Editor: These should be short, decisive observation with the notation 'for publication'. The word limit is 500 words and up to 5 references. Letters critical to an article published in the Journal must be received within 8 weeks of publication of the article.

6. Book Review: These are systemic and critical analysis of classic books of Psychiatry. The word limit in 5000 words.

7. Grand Rounds in Psychiatry (Case Conference): This should highlight one or more of the following: diagnostic processes and discussion, therapeutic difficulties, learning process or content/ technique of training. This may be authored by an individual or a team, and may be an actual case conference from an academic department or a simulated one. The word limit is 155 words and up to 10 references.

8. Viewpoint: These should be experience-based views and opinions on debatable or controversial issues that affect the profession. The author should have sufficient, credible experience on the subject. The word limit is 3000 words.

9. Commentaries: These papers should address important topics, which may either be multiple or be linked to a specific article. The word limit is 3000 words with 1 table/figure and up to 20 references.

10. My Voice: In this section multiple perspectives are provided by patients, caregivers and paraprofessionals. It should encompass how it feels to face a difficult diagnosis and what this does to relationships and the quality of life. Personal narratives, if used in this section, should have relevance to general applications or policies. Articles should underline the need to treat patients, rather than diseases, and to understand the impact such journeys may have on patients' carers and families. The word limit is 1000 words.

11. Announcements: Information regarding conferences, meetings, courses, awards and other items likely to be of interest of readers should be 
submitted with the name and address of the person from whom additional information can be obtained (up to 100 words).

Specific innovative/new ideas or newly emerging concepts for the sections are actively encouraged.

\section{STRUCTURE OF THE MANUSCRIPT}

The manuscript should be arranged in the following order, with each item beginning on a new page: (i) title page (ii) abstract (iii) text (iv) references and (v) tables and/or figures. All pages must be numbered.

\section{Title page}

The title should be brief and relevant. A short running title should be given. The number of words in the manuscript, names(s) of the author(s) and the number of tables and figures should be mentioned on the upper righthand corner of the title page. The location of work, name, degrees, designations and addresses (including e-mails) of the authors should be given along with acknowledgements in a separate paragraph. One of the authors should be designated as the corresponding author.

\section{Abstract}

It should contain no more than 250 words for an original research paper and should be no longer than 150 words for brief research communication and case reports. The abstract for original research papers and brief research communication should be organized under the following heads: background, aim, methods, results, conclusion. Up to fife key words should be given.

\section{Text}

The text should include four major sections: introduction, methods, results and discussion. The methods should present a detailed description of the nature of the study group, methods of recruitment, measurement and statistical techniques.

\section{Data analysis}

An adequate description of statistical analysis is necessary, in a language that is comprehensible to the psychiatrist as well as the medical statistician. The procedure chosen should be both appropriate for the hypothesis tested and correctly interpreted. The statistical analyses should be planned before data are collected and full explanation given for any post-hoc analysis carried out. The value of test statistics used (e.g. X2, t) should be given along with their significance levels so that their derivation can be understood. Standard deviations, rather than standard errors of the mean, are required and should be specified and referred to in parentheses.

The magnitude and direction of change should be the focus, rather than reporting a difference as being statistically significant.

\section{References}

Identify references in the text, tables and legends by Arabic numerals in superscript. References should be numbered consecutively in the order in which they are first mentioned in the text. References cited only in tables or figure legends should be numbered in accordance with the sequence established by the first identification in the text of the particular table or figure. The style of references is based on the formats used by the NLM in the Index Medicus (available from URL: http://www.incmje.org). List the first three authors followed by et al, for example:

\section{Standardjournal article}

Zubeita JK, Huguelet P, O' Neil RL, et at. Cognitive dysfunction in euthymic bipolar disorder. Psychiatry Res 2001; 102:9-20.

\section{Organization as the author}

American Psychiatric Association (APA). Diagnostic and statistical manual of mental disorders. 4" ed. Washington, DC:APA; 1994.

\section{Issue with a supplement}

Limgjaerde O. Ahlofors UG, Bech P, et at. The UKU side effect rating scale. Acta Psychiatr Scand 1987; 76 (Suppl. 334): 81-94.

\section{Chapter in a book}

Lezak MD. Assessment for rehabilation planning. In: Meier MJ, Benton AL, Diller L (eds). Neuropsychological rehabililation. London: Curchill Livingstone; 1987:41-58.

\section{Abbreviations}

Use the standardized form of abbreviation of the journal title given in the Index Medicus. For example, the Acta Psychiatrica Scandinavica becomes: Acta Psychiatr Scand. Single word titles such as Pharmacopsychiatry ar abbreviated. 
Tables

There should be a separate sheet for each table, which needs to be appropriately numbered and provided with a suitable self-explanatory heading. The desired position of the table in the manuscript should be specified. Authors should avoid tabulating data that could be expressed concisely in the text.

Tables should be double-spaced, no wider than 120 typewritten characters (including spaces) and no longer than 70 lines. Both percentages and numbers must be given. In case tables from other sources are used, due permission must be obtained.

\section{Figures}

Original, high-quality figures must be submitted. A copy of each figure and an original of each photograph must be attached with each copy of the manuscript. Figure legends should be provided on a separate page.

Each figure should be self-explanatory, visually appealing and clearly numbered. Units must be clearly indicated. Only the most widely used abbreviations are allowed. Permission must be obtained to reproduce figures from other sources. Colour figures are generally not encouraged; however, in exceptional cases, a colour figure may be accepted provided the authors explicitly indicate that they are ready to bear the additional cost of printing.

\section{Contributors' Declaration}

(To be modified as applicable and one signed copy attached with the manuscript)

MANUSCRIPT TITLEI/we certify that I/we have participated sufficiently in the intellectual content, conception and design of this work, analysis and interpretation of the data (when applicable), as well as the writing of the manuscript, to take public responsibility for it and have agreed to have my/our name being listed as a contributor. I/we believe the manuscript represents valid work. Neither this manuscript nor one with substantially similar content under my/our authorship has been published or is being considered for publication elsewhere, except as described in the covering letter. I/ we certify that all the data collected during the study are presented in this manuscript and no data from the study have been or will be published separately. I/we attest that, if requested by the editor, I/we will provide the data/ information or will cooperate fully in obtaining and providing the data/information on which the manuscript is based, for examination by the editors or their assignees.
Financial interests, direct or indirect, that exist or may be perceived to exist for individual contributors in connection with the content of this paper have been disclosed in the covering letter. Sources of outside support for the project are named in the covering letter.I/we hereby transfer, assign, or otherwise convey all copyright ownership, including any and all rights incidental thereto, exclusively to the Indian Journal of Psychiatry, in the event that such work is published by the Journal. The Indian Journal of Psychiatry shall own the work, including. 1. Copyright; 2 . The right to grant permission to publish the article in whole or in part, with or without fee; 3 . The right to produce preprints or reprints and translate into languages other than English for sale or free distribution; and 4. The right to republish the work in a collection of articles in any other mechanical or electronic format. We give the rights to the corresponding author to make necessary changes as per the request fo the journal, do the rest of the correspondence on our behalf and act as the guarantor for the manuscript on our behalf. All persons who have made substantial contributions to the work reported in the manuscript, but who are not contributors, are named in the Acknowledgement and have given me/us their permission to be named. If $\mathrm{I} / \mathrm{we}$ do not include an Acknowledgement that means $\mathrm{I} / \mathrm{we}$ have not received substantial contributions from non-contributors and no contributor has been omitted.

Name Signature Date

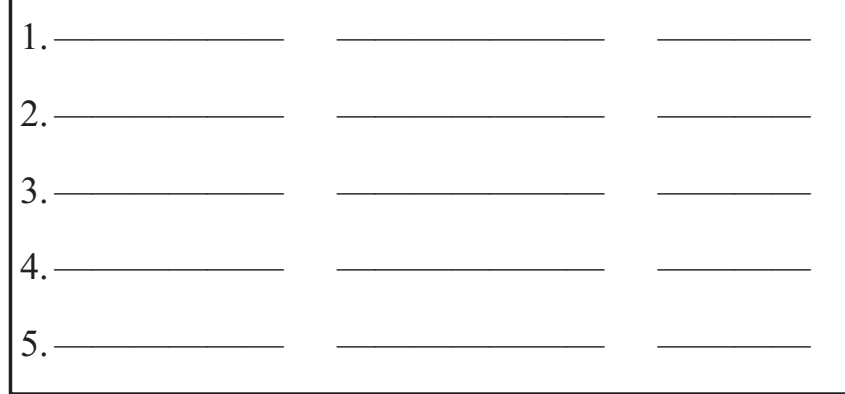

\section{Checklist for Contributors}

(To be tick marked as applicable and one copy attached with the manuscript)

\section{Manuscript title}

\section{Covering letter}

- Signed by all contributors

- Previous publications/presentations mentioned

- Source of funding disclosed

- Conflicts of interest declared 


\section{Authors}

- Names as preferred by individual authors

- Author for correspondence (with e-mail address) provided

- Number of contributors restricted as per the instructions

- Identity not revealed in the manuscript except on the title page (e.g. name of the institute in Methods, citing previous study as 'our study', names on figure labels, name of institute in photographs, etc.)

\section{Presentation and format}

- Double spacing

- Margins $2.5 \mathrm{~cm}$ on all four sides

- Title page contains all the desired information

- Running title (not more than 50 characters) provided

- Abstract provided (about 150 words for case reports and brief research communication, and 250 words for original research papers)

- Structured abstract provided for an original research paper/brief research communication

- Key words provide (up to five)

- Headings NOT in all caps

- References according to the Journal's instructions, punctuation marks checked.

\section{Language and grammar}

- Abbreviations spelt out at their first occurrence

- Numerals from 1 to 10 spelt out (except for number of patients and time lines)

- Numerals at the beginning of the sentence spelt out

\section{Tables and figures}

- No repetition of data in tables and graphs, and in the text

- Actual data from which graphs drawn, provided

- Figures necessary and of good quality (black and white)

- Table and figure numbers in Arabic letters (not Roman)

- Labels pasted on the back of photographs (no names written)

- Arrows showing the top of figures

- Figure and table legends provided (not more than 40 words)

- Patients' privacy maintained (if not, permission taken)

- Source for figures/tables provided, permission taken 
Some things in life never change

. Like your R for

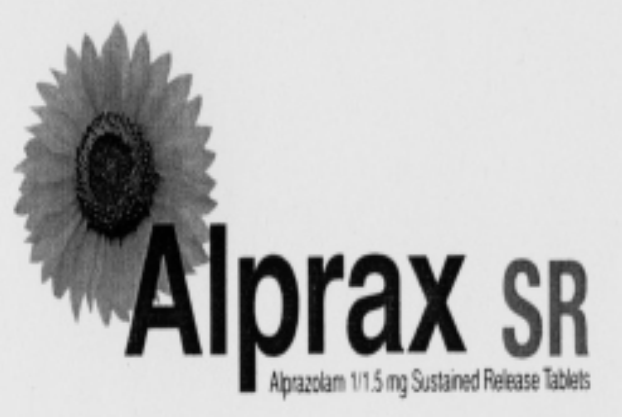

\section{Lozapin}

\section{Licab XL \\ Litium Catorals Exterded Pelease $400 \mathrm{mg}$ Tablats}

\section{Carbatol CR}

